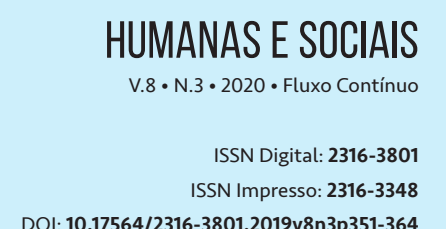

DOI: 10.17564/2316-3801.2019v8n3p351-364
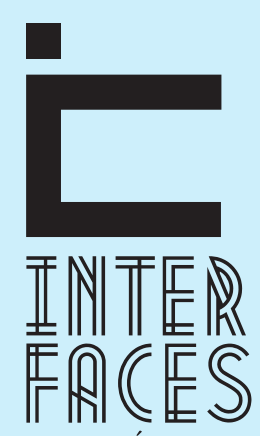

CIENTÍFICAS

\section{CURSOS PROFISSIONALIZANTES NAS PRISÕES: UTILITARISMO ECONÔMICO OU MANUTENÇÃO DO DESEMPREGO?}

PROFESSIONALIZING COURSES IN PRISONS: ECONOMIC UTILITARIANISM OR MAINTENANCE OF UNEMPLOYMENT?

CURSOS DE PROFESIONALIZACIÓNENLAS PRISIONES: ¿UTILITARISMOECONÓMICO O MANTENIMIENTODEL DESEMPLEO?
Tatiana Cavalcanti de Albuquerque Leal ${ }^{1}$ Ana Clotilde Coutinho Barbosa ${ }^{2}$

\section{RESUMO}

Este artigo tem como objetivo realizar um levantamento de quantas pessoas em livramento condicional efetivamente trabalham em ocupações nas áreas dos cursos técnicos ou profissionalizantes que haviam feito na prisão, a fim de compreender se os cursos realizados realmente fornecem perspectivas futuras aos egressos do sistema prisional. Sabe-se que a inserção do ex-detento no mercado de trabalho é marcada por sérias dificuldades e desafios relacionados aos estigmas que sofrem em decorrência da condenação a um crime. A implantação de assistência educacional dentro dos cárceres surge como estratégia para tornar os sujeitos mais capacitados para o mercado de trabalho e, consequentemente, para a vida de volta na sociedade. Em linhas gerais, foi verificado que a realização de cursos profissionalizantes forneceu perspectivas de trabalho na área destes cursos apenas para uma minoria dos sujeitos, sendo o aproveitamento direto significativamente menor para as mulheres.

\section{PALAVRAS-CHAVE}

Livramento Condicional. Cursos Profissionalizante. Prisões. Ocupações. 


\section{ABSTRACT}

This article aims to gather information on how many people on probation effectively work on occupations regarding the technical and professionalizing courses that they have taken during prison time, to comprehend if those courses could really provide future opportunities for the inmates. It is known that the egression of the ex-convict to the labor market is marked with a series of difficulties and challenges towards the stigmas they suffer from being condemned of a crime. The implantation of an education assistance inside jails arise as a strategy to become the subjects more capable to the job market and, in consequence, to a better life back into society. In general, it was verified that the accomplishment of professionalizing courses provided perspectives of work in the areas of those courses only to a minority of the subjects, and the direct outcome significantly lower to women.

\section{KEYWORDS}

Probation. Professionalizing courses. Prison. Occupations

\section{RESUMEN}

Este artículo tiene como objetivo realizar un levantamiento de cuántas personas en liberación condicional efectivamente trabajan en ocupaciones en las áreas de los cursos técnicos o de formación profesional que habían hecho en la cárcel, a fin de comprender si los cursos realizados realmente proporcionan perspectivas futuras a los egresados del sistema penitenciario. Se sabe que la inserción del expresidiario en el mercado de trabajo está marcada por serias dificultades y desafíos relacionados con los estigmas que sufren como consecuencia de la condenación a un crimen. La implantación de asistencia educativa dentro de las cárceles surge como estrategia para hacer los sujetos más capacitados para el mercado de trabajo y, consecuentemente, para la vida de vuelta en la sociedad. En líneas generales, se verificó que la realización de cursos profesionalizantes proporcionó perspectivas de trabajo en el área de estos cursos solo para una minoría de los sujetos, siendo el aprovechamiento directo significativamente menor para las mujeres.

\section{PALABRAS CLAVE}

Liberación condicional. Cursos de formación profesional. Prisiones. Ocupaciones. 


\section{INTRODUÇ̧̃̃o}

No Brasil contemporâneo, as diversas ciências sociais, como a Criminologia, têm sido demandadas a analisar e propor alternativas de ações frente a emblemáticos fenômenos sociais. No escopo do presente artigo, o tema instigador é focado no sistema prisional brasileiro, no desencarceramento e na inserção do ex-presidiário no mercado de trabalho no âmbito da Paraíba.

Segundo o Levantamento de Informações Penitenciárias - INFOPEN (DEPEN, 2014), no ano de 2014, ano em que foi finalizado o levantamento em que consistiu o presente artigo, o perfil da população carcerária no Brasil era, em sua maioria, de homens (94,2\%), negros/pretos ou pardos (61,6\%), com ensino fundamental incompleto (49,5\%) e entre 18 e 29 anos (55\%). Havia 584.758 pessoas no sistema penitenciário naquele ano.

Tem-se, voltando-se para o âmbito da Paraíba, realidade bastante próxima: em 2014, a pessoa mediana em situação de privação de liberdade também era homem (94,3\%), negra/preta ou parda (77\%), com ensino fundamental incompleto (34,6\%) e entre 18 e 29 anos (62,7\%). Havia 10.421 pessoas no sistema penitenciário naquele ano no estado (DEPEN, 2014). Note-se que a população no estado, segundo os dados, era mais jovem, mais preta/parda e menos escolarizada (inclusive mais analfabeta, sendo $19,8 \%$ no estado contra 3,9\% no Brasil nesta condição) que a média nacional.

A depender de requisitos como quantidade de pena já cumprida, bom comportamento em geral e, principalmente, disposição para encontrar uma ocupação lícita em tempo razoável, é possível antecipar a saída da prisão ao se obter livramento condicional, cumprindo-se o restante da pena em liberdade (com certas condições). Assim, a obtenção de um emprego, além de meio para perceber o capital imediato de satisfação das necessidades básicas, também serve como forma de reconhecer que aquele sujeito que reconquistou a liberdade não está mais envolvido com a criminalidade (SOUZA; SILVEIRA, 2017). Historicamente, de fato, o viés do trabalho tem sido a linha divisória entre ser cidadão e não ser, além de, em diferentes períodos, ter designado o "lugar" de cada um na sociedade.

No entanto, uma vez em liberdade, o ex-detento encontra uma série de dificuldades na inserção no mercado de trabalho, pois, ao sair da prisão, pouca ou nenhuma perspectiva de emprego lhe é dada, passando a vivenciar discriminação e rejeição. Por exemplo, na Colômbia, Ruiz (2010) verificou que as atitudes frente à inserção dos egressos do sistema no mercado eram mais favoráveis para aqueles que haviam cometido delitos tidos como mais leves. Na cidade brasileira de Fortaleza, Santos, Maciel e Matos (2013) constataram que a busca pelo trabalho de catação de lixo pelo ex-presidiário era das poucas alternativas possíveis para subsistir sem a burocracia do emprego formal, nos quais, com frequência, esse sujeito era barrado antes de assinar a carteira de trabalho por ter sido preso.

A situação é ainda mais complicada para as mulheres ex-detentas. 0 estigma por elas enfrentado é maior que o dos homens, pois sobre elas recai a crença de que devem seguir os padrões impostos socialmente, como servir ao homem e aos filhos, atender ao papel de "do lar" e não o de infringir normas e fazer parte do mundo do crime. Neste contexto, se as oportunidades de emprego a elas destinadas já poderiam ser parcas antes do encarceramento, pós-cárcere são ainda mais escassas. São poucas as que conseguem o "perdão social" e direito de voltar a participar da sociedade civil (ROSENDO; MOTA; CARVALHO; OLIVEIRA, 2018). 
É neste sentido que, para Foucault (2014), a prisão e o ideal de ressocialização são um contrassenso, pois o cárcere, enquanto busca “ressocializar”, priva os indivíduos da vida social ao excluí-los dela. Na prática, essa falência do sistema prisional brasileiro é uma realidade patente. As classes menos favorecidas socioeconomicamente é que efetivamente são atingidas pelas malhas do sistema penal, que não atingem as classes mais altas da mesma forma. Existem processos de criminalização diferentes filtrados pelo princípio da seletividade penal, sendo a prisão uma máquina de punir apenas certos comportamentos para certas classes sociais (BATISTA, 2011).

Assim, o presidiário brasileiro tem gênero, cor, idade, nível de escolaridade e tipo penal definidos - segundo o INFOPEN (DEPEN, 2014), os crimes de furto, roubo e tráfico de drogas respondem por $66 \%$ das sentenças das pessoas condenadas em 2014. No cárcere, não têm amplo acesso à assistência à saúde, jurídica, educacional ou social, como previsto na Lei de Execução Penal (BRASIL, 1984). Uma vez em liberdade e não conseguindo ser inserido no mercado de trabalho, o egresso do sistema prisional continua à margem. Sem perspectivas futuras, aumentam as chances de enxergar na criminalidade um caminho possível para subsistir.

É neste contexto que a viabilização da educação básica e profissionalizante na prisão surge como forma de dirimir tal resultado ao oferecer possíveis novas perspectivas às pessoas presas. De fato, Julião (2011) obteve que, no Rio de Janeiro, o estudo em geral, dentro do cárcere, diminuiu a probabilidade de reincidência no crime em $39 \%$. Por isso, a capacitação profissional surge como uma importante estratégia para inserir o apenado de volta na sociedade civil e no mercado.

O relatório do INFOPEN (DEPEN, 2014) assinalou que esta educação oferecida dentro dos presídios, quando de fato existe, é insuficiente: no ano de 2014 , somente $10 \%$ da população prisional brasileira participava de alguma atividade educacional de Formação Inicial e Continuada (Capacitação Profissional acima de 160 horas de aula) e 1\% de curso técnico (acima de 800 horas-aula). Na Paraíba, $5 \%$ fazia capacitação profissional e $3 \%$ da população carcerária fazia curso técnico naquele ano.

A educação na prisão parece fazer parte de uma estratégia para se atingir a grande finalidade dessa instituição: produzir corpos politicamente dóceis e economicamente produtivos (FOUCAULT, 2014), isto é, mão de obra. As próprias propostas metodológicas e curriculares dos cursos de formação profissional tendem a manter a dualidade estrutural, reproduzindo as relações de desigualdade entre as classes sociais e a serem escolas produtoras de mão de obra. Mais do que para formar os indivíduos em sua integralidade, os cursos profissionalizantes tendem a reificá-los de acordo com os interesses do capital e do mercado (DOS SANTOS; MORILA, 2018).

Por outro lado, Baratta (2002) chama a atenção para o fato de que a esperança de socializar os setores da marginalização criminal por meio do trabalho, mesmo nesta perspectiva utilitarista, se choca com a própria lógica de acumulação capitalista, que precisa manter setores marginalizados no sistema. É impossível enfrentar o problema da marginalização criminal sem ter em mente que a estrutura da sociedade capitalista necessita de desempregados. Por isto, questiona-se: são tais cursos formas de gerar sujeitos economicamente produtivos para o mercado (a socialização pelo trabalho) ou maneiras de favorecer e manter uma eventual situação de marginalização mediante opções que não oferecem perspectivas futuras de emprego? 
Embora os relatórios oficiais forneçam informações diversas sobre o panorama prisional no país, não trazem dados sobre a situação ocupacional dos apenados anteriormente ao cárcere nem tampouco acompanhamento sobre a situação posterior a ele. Neste contexto, o presente artigo teve como objetivo refletir sobre qual poderia ser o papel desempenhado pelos cursos profissionalizantes feitos nas prisões para a dita ressocialização dos sujeitos em livramento condicional. Especificamente, buscou-se averiguar qual era o nível de escolaridade dos liberados, quantos tinham feito cursos profissionalizantes, quais eram os cursos, quantos tinham algum trabalho ou ocupação e se havia relação entre o curso realizado e o trabalho assumido após a liberdade.

\section{MÉTODO}

O procedimento de coleta de dados realizado foi uma consulta às informações localizadas no banco de dados da Vara de Execução Penal da cidade de João Pessoa e aos documentos processuais das pessoas em livramento condicional que tinham sido convocadas para o atendimento psicossocial do livramento nessa Vara. Essa consulta foi feita ao longo de um ano, entre julho de 2013 e julho de 2014, e autorizada pelo juiz responsável pelas atividades do local $^{3}$.

Naquele período, foram convocados para o atendimento psicossocial da Vara 103 pessoas em livramento condicional. Foi disponibilizada a consulta aos dados e autos processuais referentes apenas a tais sujeitos. Deste total, 90 eram homens (87,3\%), com idades variando de 21 a 70 anos $(M=35,6$; $D P=10)$ e 13 eram mulheres (12,6\%), com idades variando de 27 a 69 anos $(M=42,6 ; D P=11,8)$. $A$ quantidade menor de mulheres na amostra é relativamente proporcional à quantidade menor de mutheres no sistema prisional nacional e estadual.

Foi montado um banco de dados com informações referentes a idade, sexo, nível de escolaridade, realização ou não de curso técnico/profissionalizante na prisão e profissão atual dos sujeitos. A análise descritiva dos sujeitos da amostra (frequência, porcentagem, média e desvio padrão) foi feita com o pacote estatístico Statistical Package for Social Sciences for Windows (SPSS) em sua versão 23.

\section{RESULTADOS}

A análise descritiva realizada, iniciando a apresentação dos resultados obtidos a partir do nível de escolarização, revelou a prevalência de sujeitos com ensino fundamental incompleto na amostra dos dados documentais, tanto homens como mulheres. 0 detalhamento dos níveis é apresentado na Tabela 1.

3 A pesquisa não foi submetida ao Comitê de Ética por ter se tratado apenas de um levantamento documental e processual. 
Tabela 1 - Nível de escolarização para homens e mulheres

\begin{tabular}{|c|c|c|c|c|c|}
\hline & Não alfabetizados & $\begin{array}{c}\text { Até Fund. } \\
\text { completo }\end{array}$ & $\begin{array}{c}\text { Até Médio } \\
\text { completo }\end{array}$ & $\begin{array}{c}\text { Até Sup. } \\
\text { completo }\end{array}$ & Total \\
\hline Homens & $5,7 \%$ & $76 \%$ & $17,2 \%$ & $1,1 \%$ & $100 \%$ \\
\hline Mulheres & - & $53,8 \%$ & $38,5 \%$ & $7,7 \%$ & $100 \%$ \\
\hline
\end{tabular}

Fonte: Dados da pesquisa.

Como revela a tabela, proporcionalmente, as mulheres da amostra dos registros levantados tinham níveis de escolaridade mais altos em relação aos homens: eram menos analfabetas e possuíam mais ensino médio e superior.

A fim de verificar a situação ocupacional dos sujeitos, constatou-se que, dos 103 liberados da amostra documental levantada, 84 (81,5\%) estavam trabalhando, formal ou informalmente. Considerando separadamente homens e mulheres, verificou-se que, dos 90 homens, 81 ( $90 \%$ deles) estavam trabalhando, 7 (7,8\%) encontravam-se desempregados e dois eram aposentados (2,2\%). As profissões e ocupações mais frequentes por eles assumidas são listadas na Tabela 2.

Tabela 2 - Distribuição das ocupações dos homens

\begin{tabular}{|c|c|c|}
\hline & N & \% \\
\hline Pedreiro/Servente de pedreiro & 18 & 20,0 \\
\hline Auxiliar de serviços gerais & 12 & 13,3 \\
\hline Desempregado & 7 & 7,8 \\
\hline Comerciante & 5 & 5,6 \\
\hline Motorista & 5 & 5,6 \\
\hline Autônomo & 3 & 3,3 \\
\hline Flanelinha/Lavador de carros & 3 & 3,3 \\
\hline Funcionário público & 3 & 3,3 \\
\hline Pintor & 3 & 3,3 \\
\hline Aposentado & 2 & 2,2 \\
\hline Eletricista & 2 & 2,2 \\
\hline Empresário & 2 & 2,2 \\
\hline Jardineiro & 2 & 2,2 \\
\hline Marceneiro & 2 & 2,2 \\
\hline
\end{tabular}




\begin{tabular}{|c|c|c|}
\hline & N & \% \\
\hline Técnico em prótese dentária & 2 & 2,2 \\
\hline Outras & 19 & $20,9 \%$ \\
\hline Total & 90 & 100,0 \\
\hline
\end{tabular}

Fonte: Dados da pesquisa.

Por outro lado, entre as 13 mulheres, 9 (69,2\% delas) estavam trabalhando, três (23\%) se encontravam desempregadas e duas eram aposentadas (14,4\%), como é possível verificar na Tabela 3.

Tabela 3 - Distribuição das ocupações das mulheres

\begin{tabular}{|c|c|c|}
\hline & Frequência & \% \\
\hline Auxiliar de serviços gerais & 4 & 30,8 \\
\hline Desempregada & 3 & 23,1 \\
\hline Aposentada & 2 & 15,4 \\
\hline Agente de limpeza & 1 & 7,7 \\
\hline Artesã & 1 & 7,7 \\
\hline Empregada doméstica & 1 & 7,7 \\
\hline Vendedora ambulante & 1 & 7,7 \\
\hline Total & 13 & 100,0 \\
\hline
\end{tabular}

Fonte: Dados da pesquisa.

Também foi objetivo do estudo fazer um levantamento dos cursos técnicos ou de capacitação profissional realizados (se haviam sido). Obteve-se que, considerando o total dos 103 sujeitos, apenas $21(20,3 \%)$ realizaram algum curso na prisão. Analisando novamente a partir do recorte de gênero, tem-se que, desses 21,16 eram homens (76,1\%) e 5 eram mulheres (23,8\%): ou seja, naturalmente, pela diferença quantitativa dos grupos, os homens foram maioria na realização dos cursos. Todavia, no grupo das mulheres, 5 de 13 (38,4\%) fizeram cursos, enquanto, no grupo dos homens, 16 dos $90(17,7 \%)$ os fizeram durante a reclusão. Dito de outra maneira, proporcionalmente, as mulheres fizeram mais cursos.

A área destes cursos técnicos ou profissionalizantes feitos pelos homens da amostra pode ser vista na Tabela 4, que também ensaia a relação entre o curso e a ocupação assumida por cada um deles quando adquiriram a liberdade condicional. 
Tabela 4 - Relação de cursos feitos e ocupações após o cárcere para os homens

\begin{tabular}{|c|c|c|}
\hline Liberado & Curso profissionalizante & Ocupação pós-cárcere \\
\hline 1 & Produção de vassouras & Comerciante \\
\hline 2 & Direção defensiva & Motorista \\
\hline 3 & Artesanato & Aux. serviços gerais \\
\hline 4 & Artesanato & Pedreiro/Servente de pedreiro \\
\hline 5 & Técnico em prótese dentária & Técnico em prótese dentária \\
\hline 6 & Empreendedorismo & Empresário \\
\hline 7 & Técnico em contabilidade & Motorista \\
\hline 8 & Ajustador mecânico & Funcionário público \\
\hline 9 & Eletricista & Eletricista \\
\hline 10 & Gessista & Jardineiro \\
\hline 11 & Pintor & Aux. serviços gerais \\
\hline 12 & Pizzaiolo & Comerciante \\
\hline 13 & Técnico em prótese dentária & Técnico em prótese dentária \\
\hline 14 & Confecção de bolas de couro & Aux. serviços gerais \\
\hline 15 & Confecção de bolas de couro & Aux. serviços gerais \\
\hline 16 & Vendas & Estoquista \\
\hline
\end{tabular}

Fonte: Dados da pesquisa.

Como revela a Tabela 4, dos 16 homens que realizaram curso técnico ou profissionalizante, apenas 5 (31,2\%) passaram a trabalhar, quando em liberdade, na área dos cursos: os sujeitos 2, 5, 6, 9 e 13.

Por sua vez, a relação dos cursos feitos pelas mulheres encontra-se na Tabela 5, onde também é apresentada, para cada uma delas, a ocupação assumida quando adquiriram o livramento condicional.

Tabela 5 - Relação de cursos feitos e ocupações após o cárcere para as mulheres

\begin{tabular}{|c|c|c|}
\hline Liberada & Curso profissionalizante & Ocupação pós-cárcere \\
\hline 1 & Informática e outros & Desempregada \\
\hline 2 & Preparo de doces e salgados & Vendedora ambulante de salgados \\
\hline 3 & Artesanato & Aposentada \\
\hline 4 & Corte e costura & Desempregada \\
\hline
\end{tabular}




\begin{tabular}{|c|c|c|}
\hline Liberada & Curso profissionalizante & Ocupação pós-cárcere \\
\hline 5 & Culinária & Aux. de serviços gerais \\
\hline
\end{tabular}

Fonte: Dados da pesquisa.

Conforme se apreende da listagem, apesar de terem, proporcionalmente, feito mais cursos que os homens, as mulheres seguiram menos na área em que fizeram as capacitações, de maneira que somente uma liberada (20\% do total delas) trabalhava com o objeto do curso que fez: a liberada 2, que realizou curso de "Preparo de doces e salgados" e passou a trabalhar como vendedora ambulante de salgados.

Em conjunto, os resultados indicam que a grande maioria das pessoas estava trabalhando (81,5\%), principalmente como auxiliar de serviços gerais e pedreiro/servente de pedreiro, mas somente $20 \%$ da amostra fez cursos profissionalizantes e, dos que fizeram, só $28,5 \%$ seguiu atuando na área.

Os resultados, considerando o recorte de gênero, como um todo, indicam ainda que as mulheres tinham níveis escolares mais altos (46,2\% tinham ensino médio ou superior versus $19,4 \%$ dos homens nesta condição, conforme Tabela 1$)$, fizeram, proporcionalmente, mais cursos $(38,4 \%$ delas fizeram cursos ao passo que $17,5 \%$ dos homens os fizeram), entretanto, ao saírem do encarceramento, ficavam mais desempregadas ( $23,3 \%$ não tinha ocupação declarada quando do levantamento, enquanto que $7,8 \%$ dos homens não tinha ocupação).

\section{DISCUSSÃO}

Assim como os dados revelados pelo INFOPEN (DEPEN, 2014), as informações documentais coletadas nesta amostra também indicaram a presença de uma grande maioria de sujeitos com nível escolar até o ensino fundamental, possível indicador de pertença a classes socioeconômicas mais baixas. De fato, a vulnerabilidade social não determina, mas está relacionada à prática de crimes enquanto meio para suprir as deficiências de suas condições.

Em contrapartida, embora uma interpretação mais apressada dos dados obtidos possa reforçar a concepção de que pessoas com níveis socioeconômicos mais baixos estejam mais propensas a cometer atos infracionais, existe, como lembra Batista (2011), uma seletividade penal operando no sistema de modo a punir muito mais com a privação de liberdade os crimes cometidos, em geral, por pessoas de classes mais baixas e punir de outras formas que não a prisão os delitos geralmente próprios de classes mais altas. Portanto, defende-se que não é exatamente porque os sujeitos de classes mais baixas cometeriam mais crimes que eles estariam mais presos.

No que se refere à situação ocupacional dos liberados da amostra, constatou-se que a grande maioria dos homens e a maioria das mulheres estava trabalhando, quer no mercado formal ou informal - não passa sem chamar a atenção a presença dos flanelinhas/lavadores de carros e vendedores ambulantes. Apesar disto, a incidência de desemprego entre as mulheres da amostra foi particularmente mais saliente, incluindo, neste grupo, mulheres que haviam feito cursos profissionalizantes. 
Quer dizer, enquanto todos os homens que fizeram cursos conseguiram trabalho, $40 \%$ das mulheres que fizeram cursos não conseguiram, o que sugere que possa ter havido maior dificuldade para elas alcançarem a inserção no mercado de trabalho.

A obtenção de emprego formal após ter sido condenado à prisão é um grande desafio, pois a condição de ex-presidiário carrega o estigma de que pessoas nesta condição são irrecuperáveis e não confiáveis e que irão reincidir na criminalidade mais cedo ou mais tarde. Como afirmaram Rosendo e outros autores (2018), a situação se torna ainda mais difícil para as mulheres, sob as quais os estigmas recaem de maneira mais dura, uma vez que uma mulher que cometeu um crime e foi para a prisão quebra ainda mais os padrões e as expectativas sociais do que o homem que assim o fez.

A crença de que uma das principais causas para o ingresso na criminalidade é a falta de acesso aos níveis mais altos de educação (como os próprios dados coletados nesta amostra indicaram) e de trabalho leva às iniciativas de disciplinar os sujeitos presos por meio da implantação de cursos técnicos, profissionalizantes e de aperfeiçoamento profissional dentro das prisões. Embora a presença destes cursos ainda seja insuficiente, os números levantados nos documentos mostraram resultados melhores em comparação aos dados para todo o estado da Paraíba, no sentido de que mais pessoas nesta amostra fizeram cursos na prisão.

Estes melhores indicadores, contudo, podem estar diretamente relacionados ao fato de os sujeitos da amostra estarem em livramento condicional e aos critérios para obtenção do mesmo, em que contam, além de bom comportamento, a participação em atividades laborais e educacionais, sendo o estudo também capaz de remir o tempo de pena restante dos liberados. Outra possibilidade é que a cidade de João Pessoa, particularmente, enquanto capital e município que concentra mais penitenciárias no estado, disponha de maior oferta de ensino nas prisões.

Não obstante os liberados da amostra tenham participado acima da média estadual de cursos de formação, a correspondência entre o curso ou capacitação que fizeram e os empregos e ocupações que assumiram quando em liberdade não foi realmente expressiva. Com isto, nota-se que o oferecimento dos cursos e a participação neles forneceram a uma parcela dos sujeitos, de fato, perspectivas futuras e oportunidade de capacitação profissional para atuar nas áreas da formação, mas, para a maioria, não as forneceu diretamente, pois os sujeitos não passaram a atuar na área (embora, indiretamente, possam ter contribuído de outras formas).

Quando considerada a divisão por gênero, percebe-se que mais homens do que mulheres passaram a trabalhar no âmbito dos cursos que fizeram. Novamente, o recorte de gênero evidencia uma diferença importante: além de ficarem menos desempregados, o utilitarismo proporcionado pelos cursos também foi maior para os homens, que seguiram trabalhando mais nas áreas dos cursos. Estes dados levantam o questionamento sobre a efetividade dos ditos cursos de formação profissional na chamada "ressocialização" dos liberados, especialmente as mulheres. Além disso, a oferta dos cursos parece evidenciar e reforçar o sexismo e influência dos estereótipos de gênero por meio da predominância de cursos da área de culinária e costura para as mulheres.

Outrossim, alguns cursos disponibilizados e cursados não parecem oferecer perspectivas tão promissoras de inserção no mercado de trabalho, como o de "Confecção de bolas de couro", ou favo- 
recem a inserção no mercado informal, como o de "Produção de vassouras", apontando para uma possível oferta dos cursos mais como forma de dirimir o tempo de execução das penas ou cumprir os ditames da Lei de Execução do que efetivamente proporcionar perspectivas futuras.

Também chamou a atenção os tipos de cursos oferecidos, voltados para profissões informais ou comuns às classes mais baixas, já determinando o lugar a ser ocupado pelos sujeitos posteriormente e tendendo a manter e perpetuar a dualidade estrutural e desigualdade entre as classes sociais, como cursos de ajustador mecânico e pintor.

Vale ressaltar que, embora a maioria dos sujeitos não estivesse trabalhando nas especialidades de suas capacitações, nada impede que, posteriormente, tenham conseguido empregos nessas áreas. 0 intuito do estudo não foi de acompanhar a trajetória dos indivíduos, mas tão somente apurar dados documentais das ocupações que os sujeitos possuíam quando do registro da caderneta do livramento condicional.

É importante salientar, também, que o direito à educação escolar é humano e fundamental para todos os cidadãos brasileiros, inclusive aqueles em situação de privação de liberdade e não um benefício. Portanto, para além da visão utilitarista da educação, é imprescindível vê-la também como direito fundamental e instrumento de formação individual e social, de modo que a oferta de cursos, em todos os níveis e tipos, deva ser ampliada e, principalmente, melhorada, mas é igualmente importante que seja uma educação para engrandecimento pessoal e intelectual, não apenas para formação de mão de obra.

\section{CONCLUSÃO}

De um ponto de vista utilitarista, foi verificado que a contribuição direta da realização de cursos profissionalizantes pelos sujeitos não foi realmente expressiva, pois poucos fizeram cursos e menos ainda seguiram atuando na área deles. 0 recorte de gênero foi importante: os homens egressos do sistema, quase sempre, conseguiam emprego, mas nem todas as mulheres egressas estavam trabalhando (embora, evidentemente, não se tenha como saber se o motivo foi mesmo o estigma ou outro fator). Do mesmo modo, quando faziam cursos nas prisões, os homens conseguiam mais seguir trabalhando na área e as mulheres, não. Estes dados podem evidenciar o pesado fator do estigma sofrido com mais intensidade por elas.

Neste sentido, acredita-se que, no que diz respeito à amostra utilizada, os cursos profissionalizantes feitos na prisão, para os homens, reforçaram mais o utilitarismo econômico, mesmo que não em grande escala, mas, para as mulheres, os cursos, a priori, não influenciaram de forma direta na superação do desemprego. Olhando-se de uma perspectiva mais macrossocial, questiona-se se tais resultados não estariam sugerindo que a crença na educação profissional nas prisões como potencial ressocializadora dos indivíduos estaria em xeque.

É necessário ampliar as políticas de educação prisional em geral, que, como sugerem os dados, poderiam lograr algum sucesso, mas elas precisam também ser melhoradas, bem como urge implantar políticas sociais especificamente para a superação da questão das mulheres egressas. Continuar mantendo encarcerados os sujeitos que cometeram crimes de forma que o cárcere não forneça 
quaisquer condições preparatórias para a vida em liberdade, contribuindo, incontestavelmente, para a reincidência no crime, só corrobora que a crise da prisão no Brasil, tal como a da educação segundo Darcy Ribeiro, não é uma crise, é um projeto - que coopera para os fins de nosso modelo econômico.

Aos estudos futuros, sugere-se coletas maiores e em várias prisões no país, inclusive prisões federais, bem como apurar o tipo de crime cometido e de que forma este fator se relacionaria à obtenção de emprego pós-cárcere. É interessante também que estudos posteriores possam acompanhar os liberados condicionais de modo a conhecer as principais dificuldades concretas que enfrentam em seus trabalhos, especialmente as mulheres.

\section{REFERÊNCIAS}

BARATTA, Alessandro. Criminologia crítica e do direito penal: introdução à sociologia do direito. 3 . ed. Rio de Janeiro: Revan, 2002.

BATISTA, Vera Malaguti. Introdução crítica à criminologia brasileira. Rio de Janeiro: Revan, 2011.

BRASIL. Lei n 7.210/84, de 11 de julho de 1984. Lei de Execução Penal. Disponível em: http://www. planalto.gov.br/ccivil/LEIS/L7210.htm. Acesso em: 5 ago. 2018.

DEPEN. Ministério da Justiça. Levantamento nacional de informações penitenciárias - dezembro de 2014. 2014. Disponível em: http://www.justica.gov.br/seus-direitos/politicapenal/documentos/ relatorio-infopen-mulheres.pdf. Acesso em: 25 jul. 2018.

DOS SANTOS, Manoel Tadeu Alves; MORILA, Ailton Pereira. A Educação Profissional e Tecnológica no Brasil: uma trajetória de projeções utilitaristas e seus percalços. Kiri-Kerê-Pesquisa em Ensino, n. 4, 2018.

FOUCAULT, Michel. Vigiar e punir: nascimento da prisão. 14. ed. Petrópolis: Vozes, 2014.

JULIÃO, Elionaldo Fernandes. A ressocialização por meio do estudo e do trabalho no sistema penitenciário brasileiro. Em Aberto, v. 24, n. 86, 2011.

ROSENDO, Juliana Vital; MOTA, João Luciano Marques dos Santos; CARVALHO, Grasielle Borges Vieira; OLIVEIRA, Liziane Paixão Silva. Mulheres no cárcere: breves reflexões sobre o sistema punitivo em Sergipe e os desafios da reinserção social. Interfaces Científicas-Humanas e Sociais, v. 7, n. 1, p. 107-118, 2018.

RUIZ, J. I. Actitudes sociales hacia ex reclusos: un estúdio exploratório. Suma Psicológica, v. 17, n. 2, p. 169-177, 2010. 
SANTOS, João Bosco Feitosa; MACIEL, Regina Heloisa Mattei de Oliveira; MATOS, Tereza Glaucia Rocha. Reconquista da identidade de trabalhador por ex-detentos catadores de lixo. Caderno CRH, v. 26, n. 68, 2013.

SOUZA, Rafaelle Lopes; SILVEIRA, Andrea Maria. Egressos do sistema prisional no mercado formal de trabalho: oportunidade real de inclusão social? Revista de Políticas Públicas, v. 21, n. 2, 2017. 
1 Mestra e doutoranda no Programa de Pós-graduação em Psicologia Social na Universidade Federal da Paraíba - UFPB, atuando na área de Psicologia Social da Justiça, Psicologia Política e Jurídica. Graduada em Psicologia pela Universidade Federal da Paraíba (UFPB).

E-mail: tatianacaleal@gmail.com

2 Doutora e mestre em Psicologia Social pelo Programa de Pós-Graduação em Psicologia Social da Universidade Federal da Paraíba - UFPB; Especialista em Direitos Fundamentais e Democracia pela Universidade Estadual da Paraíba - UEPB. Graduada em Psicologia pelo Centro Universitário de João Pessoa - Unipê.

E-MAIL: acoutinhopsi@gmail.com 